\title{
NOTES ON THE RELATIONSHIP BETWEEN JOB CREATION, INTERCOUNTY MIGRATION, UNEMPLOYMENT AND FAMILY INCOME
}

Robert W. Raynsford

\author{
U.S. Bureau of the Budget
}

Investigation of the reasons why people move has produced convincing evidence that to a large extent migration is related to emplayment opportunities. An interesting survey "Reasons for Moving: March 1962 to March 1953,"1 conducted by the Bureau of the Census, concluded that about $65 \%$ of migrants between 18 and 64 years of age were moving for job-related reasons. Ira Lowry of the RAND Corporation, Norking with gross migration data for Standard Metropolitan Statistical Areas, noreover, identified change in employment opportunities as one of the two most significant variables in explaining inmigration. 2 The work within the Economic Development Administration (EDA) to explain "why people move" has made use of both state and county data, For counties, no gross migration data is available so that it is not possible to explain in and outmigaation separately. Our experiments in relating county net migration to such explanatory variables as prior population growth, employment growth, per capita income, employment growth rates, and acceleration in employment, however, have indicated that these factors operate in a regular fashion for almost all counties throughout the country.

of all the combinations of explanatory variables atempted, the most satisfactory appeared to be prior population growth, employment growth rate, and employment acceleration. Parameters were estimated for a cross section including all the county units as defined by the EDA employment projection model. The equation takes the form: ${ }^{3}$

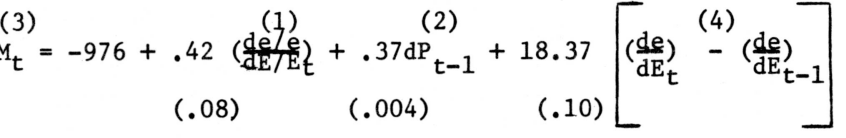

vhere $M=$ net migration in unito

$\mathrm{dP}=$ change in population in units

$\mathrm{e}=$ county employment and $\mathrm{de}=$ change in county employment

$\mathrm{E}=$ national employment and $\mathrm{dE}=$ change in national employment

$t=$ current time period

$t-1=$ previous time period

'he standard errors of the coefficients are shown in parentheses under each of the arameters respectively. The correlation matrix was:

$\begin{array}{ccccc}\text { ariable no. } & 1 & 2 & 3 & 4 \\ 1 & 1.000 & 0.227 & 0.296 & 0.253 \\ 2 & & 1.000 & 0.672 & 0.40 .6 \\ 3 & & & 1.000 & 0.920 \\ 4 & & & & 1.000\end{array}$

here variables are numbered as in the equation above. The small standard errors f coefficients, reasonably low correlation among the explanatory variables as hown by the correlation matrix, and a multiple $\mathrm{R}^{2}>.95$ for a cross section of 070 observations provide rather convincing evidence that net intercounty migration an be largely explained by these variables and related coefficients. The variables ere introduced one at a time in a stepwise regression in which order of entry was etermined by significance as measured by the F statistic. The order of signifiance was employment acceleration, previous change in population, and finally, aployment growth rate. The $F$ values for both of the first two variables were stremely high, 16892 and 6924 respectively and together account for almost all of ie explanatory power of the equation. Prior population change combines the :fects of county size and prior migration and might, therefore, have masked the splanatory power of previous migration alone had this been available. Other 
evidence, however, makes this conclusion seem less likely. First, work sheets from the Bureau of Census county population profections based on extension of prior migration rates show that quite large adjustments were necessary to make county net migration in the 1960-65 period consistent with state net migration implied by estimates of the states' populations in 1965.4 Second, our experiments using state data to develop an interstate migration function indicated that prior migration is not a useful explanatory variable.

Al1 the experiments have, in fact, led to the conclusion that net migration may be explained very largely with employment variables of several types used together. For this reason the county migration function is not only suitable to be used as a predictive device but also in simulation experiments designed to indicate the effect on migration of ppoviding additional jobs within individual counties. 5

The basic procedure is to use the county migration equation with actual county data to predict migration, modify the data to include some simulated additional employment, and compute the new predicted migration. The difference between the two sets of migration predictions will be an estimate of net migration associated with the simulated additional employment. This magnitude might be called the "migration effect". Since the migration equation was developed from cross-sectional data and does not take into account any tendency for the size of the parameters to change over time, it is preferable to use data from the same time period in performing the simulation and to circumscribe the conclusions with the caveat that they pertain explicitly to the single time period considered and only implicitly to other time periods.

The simulation has been performed three times: using 1000 additional jobs per county, 100 additional jobs per county, and additional jobs equal to one percent of county 1960 employment. All three runs produced roughly comparable results, but the last appears to be the superior procedure. Neither of the first two methods avoid having the size of the migration effect depend partially upon county size in a fashion dictated by the mechanics of the equation. 6 In the third method unwanted size effects are reduced since $-01 \mathrm{e}-1-\mathrm{a}$ constant. There still remains a very definite inverse relationship between çounty size and size of migration effect per job added, $\frac{d M}{\text { II }}$ This follows since $\frac{d}{4}=k_{i}+C .7$ This relationship, however, does not permit a very wide variation ${ }^{\prime}$ in the calculated range of migration effects per job added. If the counties are ranked from highest to lowest migration effect, and the top $5 \%$ of counties, which include the very smallest are not considered, the range is from 4.4 to 2.2 people per job. That this range is quite clearly inuersely related to county size does not diminish its plausibility. Even if one chooses to work only with the minimum implied migration effect per job, however, one is left with the conclusion that job-producing programs, insofar as they produce additional jobs for any particular county, will have a proportionately large and direct effect on net migration. 8

The relationship between the migration effect (dM) and county unemployment (U) depends upon the size of $\mathrm{dM}$ and the labor force participation rate for migrants $\left(\mathrm{LFPR}_{\mathrm{M}}\right)$. More precisely:

and

$$
\mathrm{dLF}=\mathrm{LFPR}_{\mathrm{M}}(\mathrm{dM})
$$

$U^{\prime}=U+\left(d L F-e^{\prime \prime}\right)$ where $U$ is the initial number of unemployed persons. and $U^{\prime}$ the changed number after addition of the new jobs (e") which generated dM. Only if $e^{\prime \prime}>d L F$ will $U^{\prime}<U$. Thus it follows that

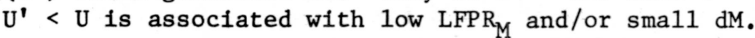

Improvements in unemployment rates (UR) are also associated with 1ow $\mathrm{LFPR}_{\mathrm{M}}$ and/or small dM but the breakeven point between improvement or deterioration on this criterion is different. In this case there will be improvement if the ratio of added jobs (e") to added labor force (dLF) is greater than the initial employment rate 1.e. $\frac{e^{\prime \prime}}{\mathrm{L} F}>\frac{\mathrm{e}}{\mathrm{L}} \overline{\mathrm{F}}$. The more stringent condition $\mathrm{e}^{\prime \prime}>\mathrm{dLF}$ no longer applies, and the worse, In terms of unemployment rate, the initial position the smaller can dIF be before the breakeven point is reached. If the initial unemployment rate were $10 \%$ the breakeven point would, of course, be defined by $\frac{e^{\prime \prime}}{d \bar{L}}=.90$. 
A plausible labor force participation rate for migrants for the 1950-1960 period can be derived quite simply from Bureau of Census Reports. 9 Net migration is reported by age groups and labor force status. It is, therefore, possible to divide migrants into those in civilian labor force and those not in the labor force. If from this latter figure all migrants over 65 years of age are subtracted on the assumption that their migration relates to their retirement plans and does not affect other family members, we can derive the population and labor force and hence ( $\operatorname{LFPR}_{M}$ ) which is relevant to considering the migration impact of additional jobs in a particular area. This LFPR appears to be a stable quantity. In 1950-51 it was .411, and 1959-60 it was .427. ${ }^{\text {M }}$ Over the entire period, therefore, .42, a figure slightly over the national overall LFPR for the period, seems appropriate.

An LFPR of .42 implies reduction in county unemployment rates $10 \%$ or greater for migration effects of less than 2.65 persons per job and reduction in numbers of persons unemployed for migration effects less than 2.37 persons per job. The results of the third simulation experiment indicate that about $58 \%$ of all counties could expect some reduction in unemployment rate if they had started from an initial position of UR $>10 \%$. Only about $29 \%$ of all counties, however, could actually reduce the number of unemployed persons within their boundaries if additional jobs $=.01 \mathrm{e}$ were added regardless of the initial unemployment rate.

If one is skeptical about the range of migration effects implied by the simulation study and wishes to work only with the lower limit of 2:2 people per job, one would conclude that if 1000 new jobs are provided, the labor force will increase by 924 and the unemployment will, therefore, be reduced by 76 persons. If jobs added were one percent of the labor force and initial $U R=10 \%$, reduction in the unemployment would be $.165 \%$ regardless of county size. Another way of expressing this conclusion is to say that jobs equal to $6 \%$ of the labor force would have to be added to reduce the unemployment rate by one percent. In the absence of a migration'effect, of course, each additional job would reduce the number of unemployed by one.

Finally the existence of a strong migration effect means that there is no simple relationship between job creation and changes in levels of county median family income. Inmigrants will raise median family or per capita income if the additional income per person arriving is greater than initial per capita income, i.e. if $\frac{d Y}{d P}>\frac{Y}{P_{t-1}}$. Inversely outmigrants will raise per capita income if the

income per person departing is less than the initial area per capita income, i.e. if $\frac{d Y}{d P}<\left(\frac{Y}{P_{t}}\right)$. Net improvement in per capita income attributable to the provision of additional jobs wil1 equal:

$$
\left.\mathrm{dM}_{0}\left(\left(\overline{\mathrm{PCI}}_{\mathrm{MO}, \mathrm{t}}-\overline{\mathrm{PCI}}_{\mathrm{MO}, \mathrm{t}-1}\right)-\overline{\mathrm{PCI}}_{t-1}-\overline{\mathrm{PCI}}_{\mathrm{MO}, t-1}\right)\right)+\mathrm{dM}_{I}\left(\overline{\mathrm{PCI}}_{\mathrm{MI}, \mathrm{t}}-\overline{\mathrm{PCI}}_{\mathrm{t}-1}\right)
$$

which equals

$\mathrm{dM}_{0}\left(\overline{\mathrm{PCI}}_{\mathrm{MO}, \mathrm{t}}-\overline{\mathrm{PCI}}_{\mathrm{t}-1}\right)+\mathrm{dM}_{\mathrm{I}}\left(\overline{\mathrm{PCI}}_{\mathrm{MI}, \mathrm{t}}-\overline{\mathrm{PCI}}_{\mathrm{t}-1}\right)$, where $\mathrm{dM}_{0}$ and $\mathrm{dM}_{\mathrm{I}}$ are the relevant

out and inmigrants and $\overline{\mathrm{PCI}}$ is average per capita income. In other words as long as the average per capita income of both the in-and-out migrant groups at time $t$ are greater than the initial PCI for the county, there will be a net improvement. This is a very plausible result for low income counties so long as the migrant groups are, in general, not disappointed in their expectations of receiving jobs. The probability of disappointment should be directly proportional to the size of the migration effect. Furthermore, disappointment among the potential outmigrant group should lead to correction through actual outmigration; whereas disappointment among the in-migrant group may not be susceptible of such easy solution. If the migration effect is generally close to 2.2 persons per job, the weight of the evidence is that county per capita income will increase in proportion to the difference between initial average income per worker and the average income per worker for the additional jobs and in proportion to the number of jobs added. That is, in this case, providing jobs should be a very effective method of raising average family or per capita income. 
County

Percentile*

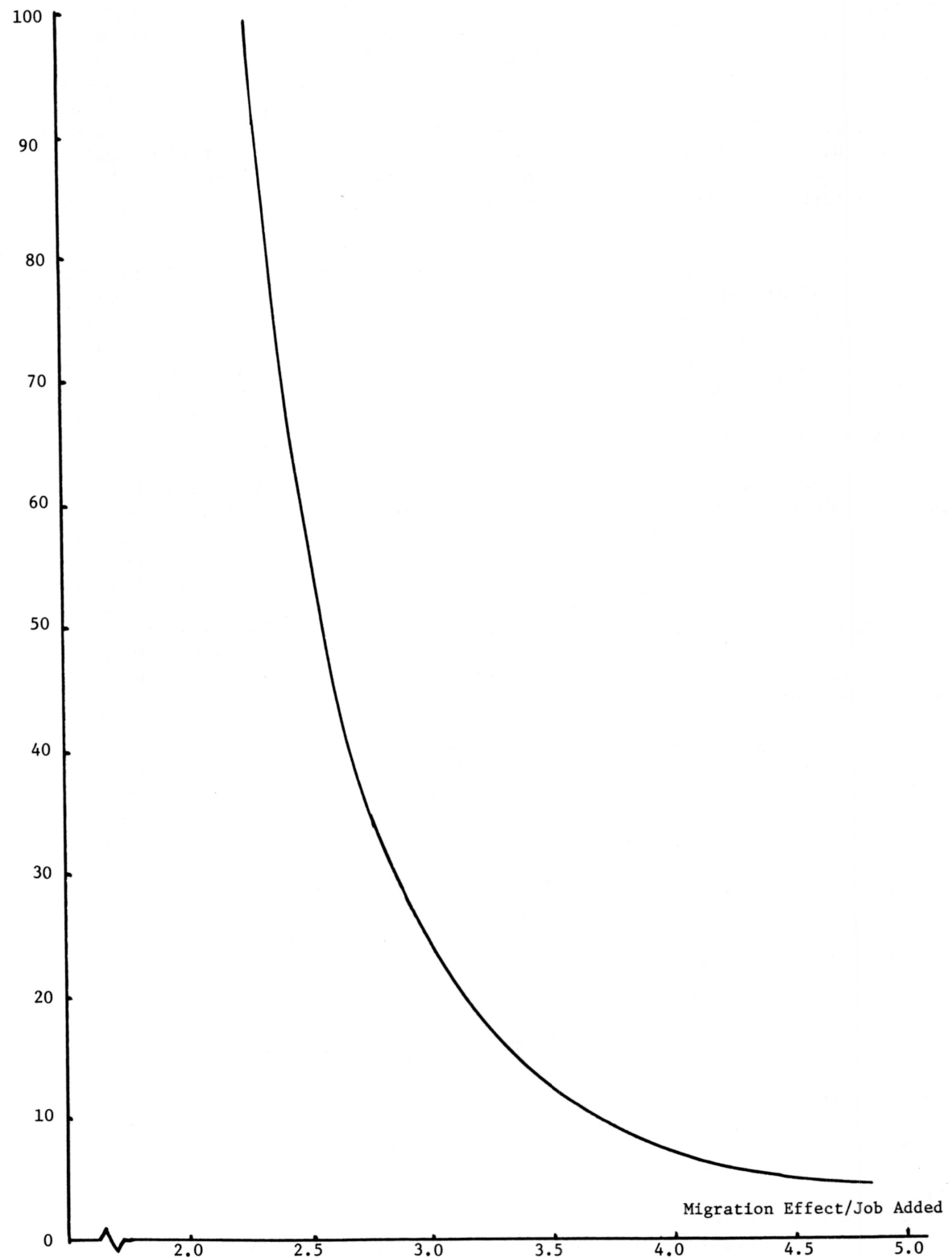

*Counties ranked by size of migration effect. 


\section{FOOTNOTES}

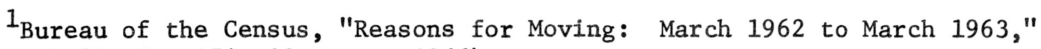
(Series P-20, No. 154, 22 August 1966).

2 Ira S. Lowry, Migration and Metropolitan Growth: Two Analytical Models.

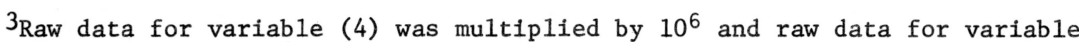
(1) was multiplied by $10^{3}$ in estimating the parameters.

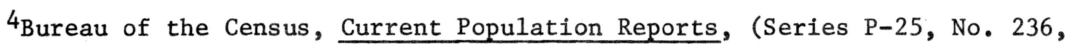
7 February 1966). For thirteen states, the control was actually greater than the estimated net migration.

${ }^{5}$ If all the statistical assumptions underlying multiple regression analysis were prefectly satisfied, one employment related variable with a small standard error of coefficient would be a perfectly adequate basis for such a simulation experiment even though this variable accounted for only a small percentage of the variation in migration. Since these assumptions, and notably lack of intercorrelation among independent variables, are fulfilled only imperfectly, the possibility of erring widely in percentage terms when relating changes in migration to changes in employment opportunities must diminish as employment related variables not only have "good fits" but also account for larger proportions of variation in the dependent variable, migration.

${ }^{6}$ Since all factors not relating to county employment are held constant in computing the simulated migration, the migration effect depends only upon changes in factors which include county employment. These are $\left(\frac{\mathrm{de}}{\mathrm{e}}\right)_{\mathrm{t}}$, which appears in

variable (1), and (de) $t$ which appears in variable (4). If the simulation run is performed by adding the same number of jobs, e.g., 1,000 per county, these factors become:

and $\mathrm{de}^{\prime}=\mathrm{de}+1,000$.

$$
\frac{\mathrm{de}^{\prime}}{\mathrm{e}^{\prime}}=\frac{\mathrm{de}+1,000}{\mathrm{e}+1,000}=\frac{\mathrm{de}}{\mathrm{e}+1,000}+\frac{1,000}{\mathrm{e}+1,000}
$$

The size of the effect attributable to the change from de to de' alone will depend only on the number of jobs added, but the effect attributable to the change to $\frac{\mathrm{de}^{\prime}}{\mathrm{e}^{\prime}}$ depends primarily on the ratio of jobs added to e, the employment.

In small counties the ratio $\frac{1,000}{\mathrm{e}+1,000}$ will be slightly less than one and in large counties less than $1 / 100$.

$$
\frac{1,000}{e+1,000}
$$

$7 \mathrm{dM}=\mathrm{f}(.01 \mathrm{e} / \mathrm{e}+.01 \mathrm{e}, .01 \mathrm{e} / \mathrm{dE})$

$$
=\mathrm{k}+\mathrm{f}\left(\mathrm{k}^{\prime} \mathrm{e}\right)
$$

but $d M / e^{\prime \prime}=k / e^{\prime \prime}+f\left(.01 e / d E . e^{\prime}\right)$

$\mathrm{dM} / \mathrm{e}^{\prime \prime}=\mathrm{k} / \mathrm{e}^{\prime \prime}+(.01 \mathrm{e}) / \mathrm{dE} \cdot(.01 \mathrm{e})$

$\mathrm{dM} / \mathrm{e}^{\prime \prime}=\mathrm{k} / \mathrm{e}^{\prime \prime}+\mathrm{C}$

8If counties are ranked by size of migration effect/job added the differences diminish in a regular fashion which indicate that a lower limit near 2.2 people/job is being approached. See Graph attached.

${ }^{9}$ Bureau of the Census, Current Population Reports, "Mobility of the Population for the United States April 1950 to April 1951," (Series P-20, No. 39) and "Mobility of the Population of the United States March 1959 to 1960," (Series $\mathrm{P}-20$, No. 113). 